\title{
Lessons Learned: Teaching and Learning Academy Workshop to promote Asset-based mindset among STEM faculty
}

\section{Dr. Daniel Galvan, California State University, Los Angeles}

Dr. Daniel Galvan is Director of Acceleration Initiatives and Student Engagement in the College of Engineering, Computer Science, and Technology at California State University, Los Angeles. He has an extensive background in facilitating asset-based approaches towards teaching through equity-minded workshops in community colleges, public, and private four-year institutions. He received his BA in Sociology from Cal Poly San Luis Obispo, his MA in Higher Education and Student Affairs from New York University, and his Ed.D. in Educational Leadership from University of Southern California.

\section{Dr. Jianyu "Jane” Dong, California State University, Los Angeles}

Jianyu Dong is a professor in electrical and computer engineering and currently serves as the Associate Dean for the College of Engineering, Computer Science, and Technology at Cal State LA. Her area of expertise is video compression/communication, multimedia networks, QoS, etc. With a strong passion in Engineering Education, she has been engaged in multiple funded projects and initiatives to increase the participation and success of students from undeserved, low-income communities in engineering areas.

\section{Dr. Lizabeth T Schlemer P.E., California Polytechnic State University, San Luis Obispo}

Lizabeth is currently a visiting professor in engineering education at Cal State LA. She is also a professor at Cal Poly, SLO in Industrial and Manufacturing Engineering. She has been teaching for 26 years and has a track record of using innovative pedagogy such as project based, flipped classroom and competency grading to support students success. Currently her research is in the area of social justice in Engineering Education.

\section{Dr. Emily L. Allen, California State University, Los Angeles}

Emily L. Allen, Ph.D., is Dean of the College of Engineering, Computer Science, and Technology at California State University, Los Angeles. She believes in a collaborative, student-centered approach to research, education, academic administration and leadership. She currently chairs the ASEE Engineering Deans Council Diversity Committee, and serves on the ABET Academic Affairs Council, the TMS Accreditation Committee, and the National Board of Directors for the Society of Hispanic Professional Engineers. Dr. Allen earned her BS in metallurgy and materials science from Columbia University, and her MS and PhD in materials science and engineering from Stanford University. She previously served as faculty, chair and Associate Dean at San Jose State University's College of Engineering. 


\title{
Lessons Learned: Teaching and Learning Academy Workshop to Promote an Asset-based Mindset among STEM faculty
}

\begin{abstract}
This lessons learned paper describes the strategies in planning, organizing, and delivering a Teaching and Learning Academy Workshop that focused on bridging the cultural and perception gap between faculty and students in math and engineering classrooms. Grounded in Yosso's Community Cultural Wealth model, the workshop was designed to engage participants in a sequence of reflective and conversational activities that allowed the faculty to connect their own educational experiences with their expectation towards the students, and recognize the strength of the students in terms of their cultural wealth in Aspirational, Linguistic, Family, Social, Navigational, and Resistance forms. The workshop received overwhelmingly positive feedback from the participants from both math and engineering departments. The success of the workshop provided preliminary yet promising answers as to how to change faculty perceptions so they are ready to "meet students where they are," which is a critical step towards the establishment of a learner-centered culture. The authors will present the paper in lightning talk format to engage the audience in an in-depth conversation following a short introduction.
\end{abstract}

\section{Introduction}

Minority-serving institutions (MSIs) play a significant role in diversifying the engineering workforce. As many students at MSIs come from underserved communities, they encounter multiple barriers that prevent them from achieving their academic goals. Although they often have good intentions to help students succeed, faculty often attribute the academic barriers to the students' lack of preparation, motivation, or effort to learn. Research studies [1] showed that this deficit mindset of instructors negatively impacts the students' self-efficacy and hinders their academic growth. A recent report from the National Academies [2] highlighted the need to create a learner-centered culture that "meets students where they are." This raises an important yet challenging question for faculty development: "What can be done to help transform faculty perception to achieve such cultural change?"

As a Very High-enrolled Hispanic Serving Institution (VHHSI), California State University, Los Angeles has 62\% Hispanic/Latino students in the College of Engineering, Computer Science, and Technology (ECST). Yet most of the STEM faculty have very different ethnic/cultural backgrounds and educational experiences from the students we serve. A critical step towards the establishment of learner-centered culture is for the instructors to recognize the cultural assets of the communities that our students belong to. The College has been offering a one-day Teaching and Learning Academy (T\&L) workshop every summer for five years, mostly for introducing evidence-based teaching pedagogies. The Summer 2019 Workshop was the first one with a very different goal: to bridge the cultural and perception gap between faculty and students in math and engineering classrooms. Grounded in Yosso's Community Cultural Wealth model [3], the workshop was designed to engage participants in a sequence of reflective and conversational activities that allowed them to connect their own educational experiences with their expectation towards the students, and recognize the students' strength in terms of their cultural wealth in Aspirational, Linguistic, Family, Social, Navigational, and Resistance forms.

The workshop participants included twenty-four tenured/tenure-track faculty and lecturers from math, various engineering disciplines, computer science, and technology, as well as six professional advisers from the ECST Student Success Center. The diverse disciplinary and 
cultural background of participants contributed to rich and lively dialogues in the workshop. Participants' feedback indicated that the workshop successfully achieved its goal, as many expressed that "the workshop was impactful and prompted them to rethink their teaching practice." The rest of the paper describes the workshop structure and activities, how participants responded to the activities, and what we learned in the planning, organizing, and implementation process.

\section{Summer Workshop Structure and Activities}

We chose to use Community Cultural Wealth (CCW) [3] as the foundational framework to design our workshop activities, since it allowed us to draw on the multiple strengths that our students bring with them, instead of focusing on the deficiencies. As a critical race theory (CRT) challenge to traditional interpretations of social and cultural capital, $\mathrm{CCW}$ offers intentional ways to shift the "traditional view of Communities of Color as places full of cultural poverty disadvantages" and recognize "the array of cultural knowledge, skills, abilities, and contacts possessed by socially marginalized groups." [3-5]. The CCW framework includes six forms of capital that are not mutually exclusive or static, but rather are dynamic processes that build on one another as part of community cultural wealth [3]:

1. Aspirational capital refers to the ability to maintain hopes and dreams for the future, even in the face of real and perceived barriers.

2. Linguistic capital includes the intellectual and social skills attained through communication experiences in more than one language and/or style.

3. Familial capital refers to the cultural knowledge nurtured among familia (kin) that carry a sense of community history, memory and cultural intuition.

4. Social capital can be understood as networks of people and community resources.

5. Navigational capital refers to the skills of maneuvering through social institutions.

6. Resistant capital refers to knowledge and skills fostered through oppositional behavior that challenges inequality.

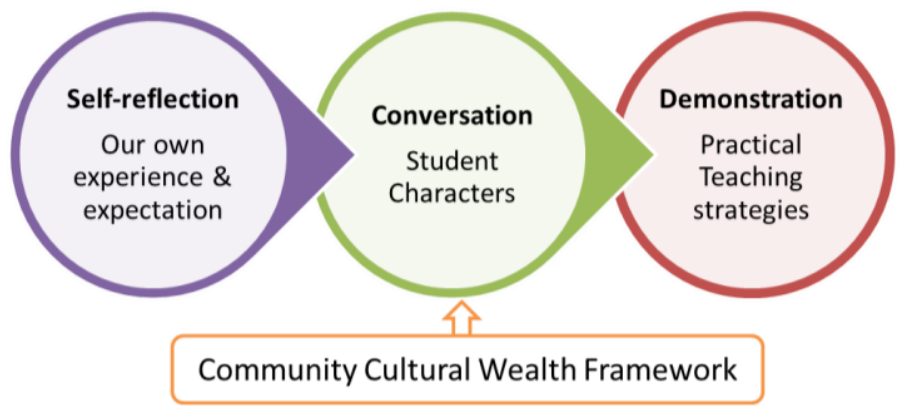

Figure 1. Structure of workshop activities

The workshop activities were designed to guide the participants to recognize our students' learning characteristics naturally and link them to the six forms of capital, as illustrated in Figure 1. The next subsections describe the activity details. Through the responses of the participants, we can see that these activities effectively drove change in their perception through iterative reflection, shared learning and discussion.

a. Reflective Activity on Participants' Own College Experience

At the beginning of the workshop, we asked the participants to take several minutes to write a reflection of their own educational experience. The goal in this exercise was two-fold: 1) to allow instructors to remember their own experiences or difficulties in maneuvering the educational system and 2) to recognize that their experience may be dramatically different than their current students. Reflection has been used in educational settings for decades as a way to solidify information, but reflection on the part of the instructors is less common. There are examples of faculty reflection making a difference in instruction because this self- 
reflection explicitly recognizes that the faculty are integral components of the system [6-8]. After spending some time writing down their experiences we asked the faculty to share with the small groups at their table. The conversation was animated and meaningful, and many participants came to realize how their own experiences shaped their expectation towards the students.

b. Better Understand Our Students Using Yosso's Model

This activity started with a table conversation about the learning characteristics of our students. Not surprisingly, a majority of the discussions was focused on the lack of preparedness of the students as well as the obstacles they faced in classes. After a quick sharing of the discussion results, the workshop facilitators used an interactive activity to introduce the various types of capitals within Yosso's Community Cultural Wealth Framework. Participants received a worksheet with various students' quotes, and a fun table activity was held to identify which types of cultural wealth capital was present in a specific quote. There was a high level of engagement when the participants found out that the quotes came from "real student expression" that described their classroom experiences. This activity allowed the participants to gain the ability to recognize and acknowledge various examples of the cultural wealth that students carry with them. As a follow-up exercise, each table resumed their conversation about student learning characteristics, and many strengths were identified as shown in Figure 2. This showed that many participants changed their view of the students after learning about the CCW model.

c. Design Courses based on Students' Strength

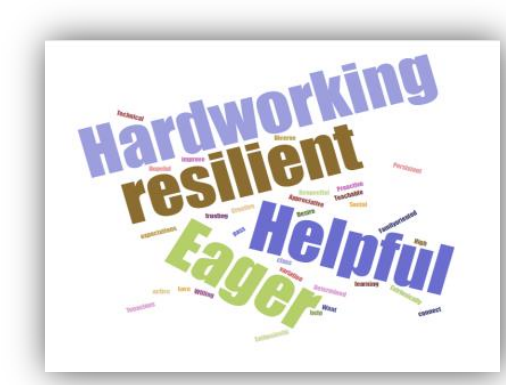

Figure 2. Faculty perception of students' strength after the CCW activity.

The goal of this activity was to introduce pedagogical techniques that draw on students' assets. By demonstration of relevant examples, the facilitator showed a list of potential activities:

- Ask students at the beginning of class to share with you their aspirations for their future. This can be done with a short written reflection activity. It will remind them that you care about their aspirations and that they have long term goal in mind (Aspirational capital).

- Announce on the first day that it is acceptable to speak to each other in any language that they find comfortable (Linguistic Capital).

- Create an outreach project or homework that gives students the opportunity to connect with individuals in their community or family regarding the class subject (Familia Capital).

- Assignments that require students to connect with a professional engineer or alumni for an interview could help expand a network for the students (Social Capital).

- Changes in grading practices, such as forms of mastery grading, could help students use their resistant capital where they can master content through multiple tries at exams [9].

\section{Participant Feedback}

To measure the effectiveness of the workshop, quantitative and qualitative feedback was collected through participant surveys with open-ended questions, as well as informal conversation afterwards. The quantitative results in Table 1 indicated a high level of satisfaction with the workshop experiences, as well as the outcomes. 
Table 1. Participants' rating of their overall workshop experiences

\begin{tabular}{l|ccccc}
\hline & $\begin{array}{c}\text { Strongly } \\
\text { agree }\end{array}$ & Agree & Neutral & $\begin{array}{c}\text { Disagree } \\
\text { Strongly } \\
\text { Disagree }\end{array}$ \\
\hline I better understand my students' learning characters. & $67 \%$ & $22 \%$ & $11 \%$ & $0 \%$ & $0 \%$ \\
\hline I enjoyed connecting with colleagues during the event & $89 \%$ & $11 \%$ & $0 \%$ & $0 \%$ & $0 \%$ \\
\hline $\begin{array}{l}\text { I learned useful strategies/ideas that I can apply in the } \\
\text { future. }\end{array}$ & $78 \%$ & $11 \%$ & $11 \%$ & $0 \%$ & $0 \%$ \\
$\begin{array}{l}\text { I will recommend my colleagues to participate in future } \\
\text { Teaching and Learning Academies }\end{array}$ & $89 \%$ & $11 \%$ & $0 \%$ & $0 \%$ & $0 \%$ \\
\hline
\end{tabular}

Qualitative results revealed that the "most useful take-aways" from the workshop included "practical learner-centered strategies," "suggestions and shared-learning with peers/facilitators," and "Community wealth and student characteristics." The findings were reinforced by the follow-up conversation with faculty participants. In particular, they reported that the "diverse perspectives from their colleagues (faculty and advisers) really helped them better understand our students" and "prompted them to rethink their way of teaching."

\section{Lessons Learned and Conclusions}

Through the workshop organization and participant feedback, we summarized the following useful strategies: 1) set up the workshop goals based on the needs of targeted faculty - we conducted a survey among ECST faculty to gauge their interest and designed the workshop accordingly. This is also critical to attract participants; 2) build activities based on proper theoretical framework - while introducing theories in social science or education (e.g. CCW) can be challenging to STEM faculty, it actually helped to create a credible and systematic learning process; 3) engagement is key - a successful workshop should be a live demo of learner-centered active learning strategies; 4) diversity in the participants truly enriched the workshop experience. We hope the lessons learned can provide insight to address some common challenges faced by faculty developers, such as limited participation, especially in institutions where professional development is optional, and STEM faculty reluctance to adopt active learning strategies.

\section{Reference}

[1] Rattan, A., Good, C., \& Dweck, C. S. (2012). "It's ok - Not everyone can be good at math": Instructors with an entity theory comfort (and demotivate) students. Journal of Experimental Social Psychology, 48(3), 731-737. doi:10.1016/j.jesp.2011.12.012

[2] "Minority Serving Institutions: Americas' Underutilized Resource for Strengthening the STEM Workforce," The National Academies Press, Washington DC (2019). DOI: https://doi.org/10.17226/25257

[3] Yosso, T. J. (2005). Whose culture has capital? A critical race theory discussion of community cultural wealth. Race ethnicity and education, 8(1), 69-91.

[4] Smith, J. M., \& Lucena, J. C. (2016). Invisible innovators: how low-income, first-generation students use their funds of knowledge to belong in engineering. Engineering Studies, 8(1), 1-26.

[5] Valenzuela, A. (1999). Subtractive schooling: Issues of caring in education of US-Mexican youth. State University of New York Press.

[6] Harding, T.,at el, (2015) The Role of Collaborative Inquiry in Transforming Faculty Perspectives on Use of Reflection in Engineering Education. Paper presented at the Frontiers in Education Conference, El Paso, TX October 2014.

[7] Ruth, D. (2013). Teaching strategy: reflections on professional practice. Teaching in Higher Education, 19(3), $254-265$. http://doi.org/10.1080/13562517.2013.860100

[8] Schlemer, L.T., DeGreef*, L. \& Harding, T. (2017) "Stories of Change: Faculty in reflective Dialogs,"

Presentation and Paper at ASEE Annual Meeting, Columbus OH. * Student authorship

[9] Schlemer, L.T. \& Vanasupa, L.S., "Grading for enhanced motivation and learning” Presentation and Paper ASEE Annual Meeting, New Orleans, LA, June 2016. 